point of some importance, as Stevenson et al. (1971) suggested that the IgE immunoglobulins of the newborn may be less able to fix to dermal cells or to participate in the anaphylactic process than those of the older infant. The infant at 3 to 5 weeks of age, however, reacts to anti-IgE with weal-and-flare skin responses (Stevenson et al., 1971). It is therefore likely that the infant should have an efficient IgE cell-fixing and histamine-releasing system by 2 to 3 months of age, when the prevalence of S.I.D. is maximal.

The continued epidemiological and pathological findings in S.I.D. suggest that it has a multifactorial aetiology. Whether anaphylaxis induced by hypersensitivity to these or as yet other unidentified allergens can fully explain these deaths remains unproved. There is little doubt, however, that this study has shown by an in-vitro assay a significant difference between S.I.D. and control infants of the same age.

This work was supported by grants from the National Health and Medical Research Council, the Princess Margaret Children's Medical Research Foundation, and the Asthma Foundation of Western Australia. We are grateful to Miss E. Quinn, Miss J. Butler, and Mr. C. Raven for skilled technical help. The cooperation of the coroners, the Commissioner of Police, and the Commissioner of Public Health of Western Australia is gratefully acknowledged.

Requests for reprints should be addressed to: Dr. K. J. Turner, Clinical Immunology Unit, Princess Margaret Hospital, Perth, Western Australia.

\section{References}

Aas, K., and Johansson, S.G.O. (1971). Fournal of Allergy and Clinical Immunology, 48, 134

Baldo, B. A., Turner, K. J., and Quinn, E. (1975). Unpublished observations.

Bazaral, M., and Hamburger, R. N. (1972). Fournal of Allergy, 49, 189.

Gold, E., and Godek, G. (1961). American fournal of Diseases in Children, 102,542 .

Gunther, M. (1972). In Sudden and Unexpected Deaths in Infancy (Cot Deaths), ed. F. E. Camps and R. G. Carpenter, p. 15. Wright, Bristol.

Hilton, J. M. N., and Turner, K. J. (1974). "Sudden death in Infancy Syndrome in Western Australia." Submitted for publication.

Ishizaka, K., and Ishizaka, T. (1967). Fournal of Immunology, 99, 1187.

Johansson, S. G. O., Bennich, H. H., and Berg, T. (1972). In Progress in Clinical Immunology, ed. R. S. Schwartz, vol. 1, p. 157. N.Y., Grune

Johansson, S. G. O., Bennich, H. H., and Wide, L. (1968). Immunology, $14,265$.

Johnstone, J. M., and Lawy, H. S. (1966). British Medical Fournal, 1, 706. Kletter, B., et al. (1971). Clinical Allergy, 1, 249.

Lumpkins, E. D., Corbit, S. L., and Tiedeman, G. M. (1973). Annals of Allergy, 31, 361 .

Miller, D. L., Hirvonen, T., and Gitlin, D. (1973). Fournal of Allergy, 52, 182.

Mulvey, P. M. (1972). Medical fournal of Australia, 2, 1240.

Parish, W. E., Barrett, A. M., and Coombs, R. R. A. (1960). Immunology, 3, 307.

Parish, W. E., et. al. (1964). International Archives of Allergy and Applied Immunology, 24, 215.

Rowe, D. S., et. al. (1970). Bulletin of the World Health Organization, 43, 609.

Stenius, B., and Wide, L. (1969). Lancet, 2, 445.

Stenius, B., et. al. (1971). Clinical Allergy, 1, 37.

Stevenson, D., et. al. (1971). Fournal of Allergy and Clinical Immunology, 48, 61.

Turner, K. J., Rosman, D., and O'Mahony, J. (1974). International Archives of Allergy and Applied Immunology, 47, 650 .

Turner, K. J., et. al. (1975 a). Unpublished observations.

Turner, K. J., Baldo, B. A. and Anderson, H. R., (1975 b). Submitted for publication.

Wide, L., Axen, R., and Porath, J. (1967 a). Immunochemistry, 4, 381.

Wide, L., Bennich, H., and Johansson, S. G. O. (1967 b). Lancet, 2, 1105.

\title{
Peak Expiratory Flow in Youths with Varying Cigarette Smoking Habits
}

\section{I. BACKHOUSE}

British Medical fournal, 1975, 1, 360-362

\section{Summary}

Measurements of peak expiratory flow (P.E.F.) were done on 195 boys arriving at a detention centre, and again eight weeks later at the time of their discharge. During this time they took much physical exercise, and cigarette smoking and drug taking were not permitted.

At the initial assessment there was an impairment of P.E.F. inversely proportional to the amount of cigarettes smoked which was statistically significant.

There was a significant improvement in P.E.F. between reception and discharge in all groups of boys with varying smoking habits, all groups except the heavy smokers achieving near normal results after eight weeks. The heavier smokers improved more than the non-smokers or light smokers, but this difference was not statistically significant. Suggested reasons for this improvement are discussed.

\section{Introduction}

This study was conducted in a detention centre on youths aged $16-20$ years. Most $(89 \%)$ were cigarette smokers. The youths

The Surgery, Kingston Avenue, East Horsley, Surrey KT24 6QT C. I. BACKHOUSE, M.B., D.OBST.R.C.o.G., General Practitioner and
Medical Officer Home Office studied were delinquent boys, who before arriving at the centre probably smoke more and probably have less opportunity and enthusiasm for physical exercise than youths of the same age seen in the general population. Most are from social classes III-V.

The routine in the centre gives much emphasis to physical exercise, regular meals, and sleep. Smoking is not permitted during their stay, and this is enforced by rigid supervision. There is, thus, an unusual opportunity to show any change in ventilatory function that might be attributed to smoking by comparing results obtained on their arrival with those on their discharge some eight weeks later.

\section{Method}

At the medical examination on reception all boys who were likely to stay for at least eight weeks and who had no gross physical disablement and no past or present history of asthma were accepted for the study. They were recruited as they were received, consecutively over a period of six months. The aim was to study 200 boys but though 215 were recruited 20 were incompletely studied because they were transferred to other establishments or because of illness at the time of discharge. This left 195 boys with completed data.

The following data was collected from each boy on arrival at the centre (and again on discharge eight weeks later in the case of peak expiratory flow (P.E.F.) measurements): (a) physical characteristics - that is, age, height, and weight (stripped); (b) the average daily cigarette consumption in the three months before reception, by careful direct inquiry; $(c)$ any abuse of drugs, including the smoking of cannabis. A boy was considered 
to be a drug taker if he had abused drugs on at least two days a week regularly in the previous three months; (d) P.E.F., measured with the Wright peak-flow meter. Six readings were taken over about five minutes and the mean of the best three readings was recorded.

\section{Results}

Physical Characteristics. - The sample studied showed ages ranging between 16 and 20 years with a mean age of 18 years (table I). Their heights at reception ranged between 63 inches $(160 \mathrm{~cm})$ and 74 inches $(188 \mathrm{~cm})$, with a mean of 68.6 inches $(174.8 \mathrm{~cm})$. No height measurements were taken at the end of the period in custody. The measurement of weight was done twice for most boys. The mean weight $( \pm$ S.D.) at reception in the 195 boys was $146.4 \pm 21.7 \mathrm{lb}(66.5 \pm 9.9 \mathrm{~kg})$ and that at discharge in 177 boys was $149.8 \pm 18.8(68 \pm 8.5 \mathrm{~kg})$. While the change in the mean was not significant the change in standard deviation was. This is much as would be expected from an establishment where a balanced diet and regular exercise are enforced as these have the effect of building up the underweight and reducing the overweight.

Smoking and Drug-taking Habits.-Boys were classified into different groups according to the average amount they had smoked each day in the previous three months (table II). There seemed to be some relation between smoking and drug taking. The greater the quantity of cigarettes smoked by any individual the more likely he was to have some drug involvement. This was noted before in a study of these habits in junior detention centre boys aged 14-16 in 1967-8 (Backhouse and James, 1969). The 17 drug takers formed $8 \cdot 7 \%$ of this sample. This was a smaller percentage than noted in previous surveys in this centre, but occasional drug abusers were not classified as drug takers and were, therefore, not included. The age average of this group of drug takers was 18.3 years. The types of drug abused were as follows: seven boys took cannabis only, two took cannabis and amphetamines, five took cannabis and lysergide (LSD), two took amphetamines and barbiturates, and one took cannabis, LSD, and heroin. Thus 15 of the 17 boys took cannabis, either alone or with other drugs.

TABLE I-Age Distribution in 195 Boys

\begin{tabular}{l|c|c|c|c|c|c}
\hline $\begin{array}{l}\text { Age (years) } . . \\
\text { No. (\%) of boys }\end{array}$ & $3(1 \cdot 5)$ & 75 (38.5) & $55(28 \cdot 2)$ & $49(25 \cdot 1)$ & $13(6 \cdot 7)$ & $195(100)$ \\
\hline
\end{tabular}

TABLE II-Smoking and Drug Taking in 195 Boys

\begin{tabular}{|c|c|c|c|c|c|}
\hline \multicolumn{3}{|c|}{$\begin{array}{c}\text { No. of } \\
\text { Cigarettes } \\
\text { Smoked/Day }\end{array}$} & \multirow{2}{*}{$\begin{array}{l}\begin{array}{l}\text { No. (\%) } \\
\text { of Boys }\end{array} \\
22(11) \\
19(10) \\
41(21) \\
68(35) \\
45(23)\end{array}$} & \multirow{2}{*}{$\begin{array}{c}\begin{array}{c}\text { Mean Age } \\
( \pm \text { S.D. }\end{array} \\
\text { in Years } \\
18.2 \pm 0.92 \\
17.6 \pm 1.01 \\
18.1 \pm 1.08 \\
17.8 \pm 0.93 \\
18.0 \pm 0.97\end{array}$} & \multirow{2}{*}{$\begin{array}{c}\begin{array}{c}\text { No. (\%) of } \\
\text { Drug Takers } \\
\text { in Each Group }\end{array} \\
1(5) \\
1 \text { (5) } \\
3 \text { (7) } \\
7(10) \\
5(11)\end{array}$} \\
\hline $\begin{array}{l}0 \ldots \\
1-9 \\
10-19 \\
20-29 \\
\geqslant 30\end{array}$ & $\begin{array}{l}. \\
\therefore \\
\therefore\end{array}$ & $\begin{array}{l}\ldots \\
\cdots \\
\cdots\end{array}$ & & & \\
\hline \multicolumn{3}{|c|}{ Total } & $195(100)$ & $18.0 \pm 0.98$ & $17(8 \cdot 7)$ \\
\hline
\end{tabular}

Peak Expiratory Flow.-The mean P.E.F. in groups of boys with varying smoking habits on reception and again after eight weeks' stay in the centre is shown in table III. Because cannabis is an inhaled drug the 15 cannabis takers were also analysed as a separate group: their mean P.E.F. $( \pm$ S.D.) on reception was $539 \pm 711 . / \mathrm{min}$, and eight weeks later it was $578 \pm 711 . / \mathrm{min}$. Since there is a relationship between P.E.F. and the age and height of the subject the P.E.F. of each boy was also calculated as a percentage of his predicted value $(100 \%)$, which was derived from a nomogram of normal values of P.E.F. based on the findings of Gregg and Nunn (1973). The P.E.F. results on reception showed an impairment of P.E.F. inversely proportional to the daily amount of cigarettes smoked (table IV). This was analysed using a one-way analysis of variance and found to be statistically significant $(F=3.91 ; P<0.05)$, but the correlation coefficient was only $-0 \cdot 14$. At the time of discharge from the centre eight weeks later all groups showed a significant improvement in P.E.F., particularly the heavier-smoking groups. All groups except the heavy smokers had almost achieved their predicted P.E.F. by the time of discharge. Though there was a greater improvement in heavier smokers than in non-smokers this difference was not statistically significant. It was not, therefore, possible to attribute this improvement to giving up smoking, but the results do suggest that this was a contributory factor.

TABLE III-Mean P.E.F. ( \pm S.D.) in Youths grouped according to Smoking Habits

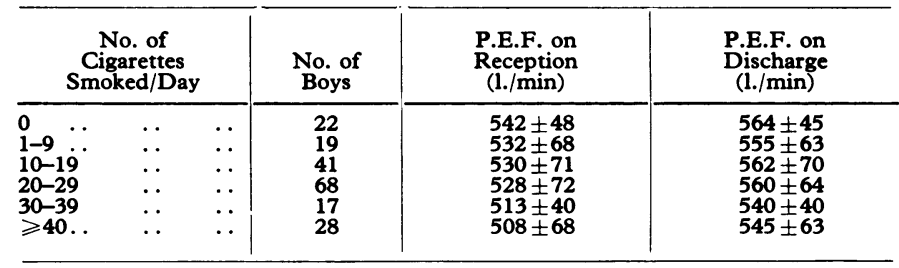
TABLE IV-Mean P.E.F. ( \pm S.D.) corrected by Age and Height expressed
as Percentage of the Predicted Values (Gregg and Nunn, 1973) in 195 Boys with Varying Smoking Habits

\begin{tabular}{|c|c|c|c|c|c|c|}
\hline \multicolumn{3}{|c|}{$\begin{array}{c}\text { No. of } \\
\text { Cigarettes } \\
\text { Smoked/Day }\end{array}$} & \multirow{2}{*}{$\begin{array}{c}\begin{array}{c}\text { No. of } \\
\text { Boys }\end{array} \\
22 \\
19 \\
41 \\
68 \\
17 \\
28 \\
\end{array}$} & \multirow{2}{*}{ 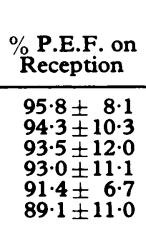 } & \multirow{2}{*}{ 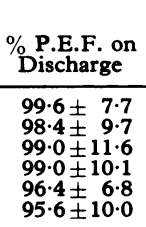 } & \multirow{2}{*}{$\begin{array}{c}\begin{array}{c}\% \\
\text { Improvement }\end{array} \\
3.8 \\
4.1 \\
5.5 \\
6.0 \\
5.0 \\
6.5\end{array}$} \\
\hline $\begin{array}{l}0 . \\
1-9 \\
10-19 \\
20-29 \\
30-39 \\
\geqslant 40\end{array}$ & $\begin{array}{l}\ldots \\
\because \\
\because \\
\therefore\end{array}$ & $\begin{array}{l}\ldots \\
\because . \\
\because . \\
\ldots\end{array}$ & & & & \\
\hline \multicolumn{3}{|c|}{ Cannabis smokers } & 15 & $94 \cdot 1 \pm 11 \cdot 0$ & $100.9 \pm 9.5$ & 6.8 \\
\hline
\end{tabular}

\section{Discussion}

The P.E.F. results in all the smoking groups and in the nonsmokers are lower than those reported in the general-practice study of Gregg and Nunn, which was on non-smokers from a middle-rlass London suburb. There are several reasons apart from cigarette smoking why this might be so. Firstly, this study was of delinquent youths of predominantly low social class, and the P.E.F. is known to vary with social class (Holland et al., 1969). Secondly, many of these boys came from large families and resided in the poorer parts of London and other cities in the south of England, where atmospheric pollution is likely to be higher than elsewhere. Thirdly, the low initial results could have been due partly to poor thoracic and abdominal musculature. Certainly inquiry in the past has shown that these boys take very little regular exercise before arrival at the centre. A weight gain is noted in the eight-week period and it is probable that the increased physical exercise is responsible for some general increase in musculature. Fourthly, in this study the P.E.F. was taken as the mean of the highest three figures obtained from six attempts whereas most other studies have taken the highest figure of three attempts.

All groups showed an improvement in P.E.F. after eight weeks in the centre. Some improvement in P.E.F. can probably be explained by familiarity with the use of the peak flow meter at the time of the secona assessment. There may also be some increased enthusiasm in each individual to improve on his past performance.

It seems, however, that there is some impairment of initial P.E.F. due directly to cigarette smoking and that in this age group this is largely reversible by the end of an eight-week 
period which includes much physical exercise and abstention from cigarette smoking. In this study only the heavy smokers failed to get back to normal in this short period though they showed the biggest percentage improvement. Earlier observation in this centre showed that, as would be expected, the heavy smokers were more likely to have begun smoking at an earlier age than lighter smokers. The impaired P.E.F. in heavy smokers and its failure to return to normal may be due to changes in the bronchial tubes dependent not only on the amount of cigarettes smoked but also on the number of years the individual had been a smoker. It is interesting that any changes at all can be detected in such young people, most of whom cannot have been smoking for many years.

The cannabis smokers, most of whom were moderate or heavy cigarette smokers, surprisingly showed initial figures as good as the non-smokers. Their percentage improvement, however, was the highest of all groups. Nevertheless, the numbers involved were too small to be of any significance.

The findings of P.E.F. in the non-smokers and light smokers on discharge agreed closely with the normal values of P.E.F. found in strictly normal subjects in this age group by Gregg and Nunn (1973).

I thank hospital officer C. S. Clark for his help in conducting this survey; Dr. Ian Gregg, director of the department of clinical epidemiology in general practice, Cardiothoracic Institute, Brompton Hospital, London, for his encouragement and advice; Dr. Michael D'Souza of the department of clinical epidemiology and social medicine, St. Thomas's Hospital Medical School, London, for the statistical analysis and his helpful criticisms; and the statistical department of the Home Office.

\section{References}

Backhouse, C. I., and James, I. P. (1969). British fournal of Addiction, 64,

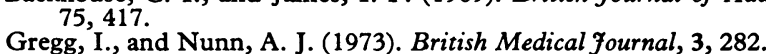

Holland, W. W., et al. (1969). Millbank Memorial Fund Quarterly, 47, 215.

\title{
Early Discharge of Infants of Low Birth Weight: A Prospective Study*
}

\author{
B. SINGER, JACK WOLFSDORF
}

British Medical fournal, 1975, 1, 362-364

\section{Summary}

A total of 495 African infants of low birth weight were discharged from Harari Maternity Hospital, Salisbury, between October 1972 and September 1973. Criteria used for discharge were (a) no clinical evidence of disease, (b) satisfactory feeding by mouth (breast or bottle or both), and (c) stable temperature control under normal room conditions. Of the 495 babies 264 fulfilled these criteria when they weighed 1801-1900 g (group 1), 99 when they weighed 1901-2000 g (group 2), and 132 (group 3) when they weighed $2001-2500 \mathrm{~g}$. The overall follow-up rate of those infants living in greater Salisbury was $85.5 \%$, the health visitor playing an important contributory role in their progress, especially those in group 1.

More than two clinic visits in the first four to five weeks after discharge were essential for continuing weight gain in groups 1 and 2 but not in group 3. The mean daily weight gain for all babies at the end of four to five weeks was $26 \mathrm{~g}$.

Readmission rates for babies in groups 1, 2, and 3 were $9.5 \%, 1 \%$, and $0.8 \%$, respectively, the largest single cause for readmission being bronchopneumonia associated with hypothermia. Altogether $60 \%$ of the readmissions occurred during the two winter months (June and July). Hypothermia, associated with low environmental temperatures, played a significant part in morbidity and mortality, and twins, particularly in group 1, had a

\footnotetext{
Department of Paediatrics and Child Health, Godfrey Huggins School of Medicine, University of Rhodesia, Salisbury, Rhodesia B. SINGER, M.R.C.P., D.C.H., Consultant

JACK WOLFSDORF, DIP.PAED., F.R.C.P., Professor
}

mortality rate three times greater than singletons in the same group.

In general, even in underdeveloped communities singleton babies born outside the winter months with reasonable clinic or home visiting facilities can be discharged at a weight of $1800 \mathrm{~g}$ or more.

\section{Introduction}

The alarming population explosion that is still occurring in underdeveloped countries despite various attempts to limit population growth places a heavy burden on neonatal hospital beds and medical and nursing personnel. In Rhodesia the African population has increased from 4.1 to 5.7 million since 1964 (Central Statistical Office, 1973), and while $80 \%$ of the population live in rural areas many people congregate around the main cities. In Salisbury Harari Maternity Hospital is the only referral teaching maternity hospital in a $250-\mathrm{km}$ radius. Each year about 7500 referred, "prescreened," or "at risk" mothers deliver their infants in this hospital, almost half of the babies subsequently requiring management in the neonatal unit. The neonatal unit comprises 60 beds run by the department of paediatrics and includes intensive-care, transitional-care, isolation, and "well-baby" wards.

Of all the babies born in the hospital $12-17 \%$ weigh less than $2500 \mathrm{~kg}$. After recovering from their immediate postnatal problems these babies normally need to stay in hospital for feeding until an adequate discharge weight (and thus maturity) is achieved. At any time $60 \%$ of the babies in the neonatal unit fall within this category (J. Wolfsdorf and B. Singer, unpublished data). The increased mortality from infections associated with overcrowded nurseries and the costs involved in keeping patients in hospital who might be managed on an ambulatory basis prompted us to undertake a year's prospective study of babies discharged at lower than customary weights. Follow-up for the first four to five weeks after discharge was undertaken. 